\title{
The association of dialysis adequacy, body mass index, and mortality among hemodialysis patients
}

\author{
Woong-pyo Hong and Yu-Ji Lee* (B)
}

\begin{abstract}
Background: Although hemodialysis (HD) adequacy, single-pool Kt $/ \mathrm{N}_{\text {urea }}(\mathrm{spKt} / \mathrm{N})$, is inversely correlated with body size, each is known to affect patient survival in the same direction. Therefore, we sought to examine the relationship between HD adequacy and mortality according to body mass index (BMI) in HD patients and explore a combination effect of BMI and $\mathrm{HD}$ adequacy on mortality risk.

Methods: We retrospectively reviewed patient data from the Korean Society of Nephrology registry, a nationwide database of medical records of HD patients, from January 2001 to June 2017. We included patients $\geq 18$ years old who were receiving maintenance HD. Patients were categorized into three groups according to baseline BMI $(<20$ (low), 20 to $<23$ (normal), and $\geq 23$ (high) $\mathrm{kg} / \mathrm{m}^{2}$ ). Baseline spKt $N$ was divided into six categories.

Results: Among 18,242 patients on HD, the median follow-up duration was 5.2 (IQR, 1.9-8.9) years. Cox regression analysis showed that, compared to the reference (spKt/N 1.2-1.4), lower and higher baseline spKt/N were associated with greater and lower risks for all-cause mortality, respectively. However, among patients with high BMI $(n=5588)$, the association between higher spKt $\mathrm{N}$ and lower all-cause mortality was attenuated in all adjusted models $\left(P_{\text {interaction }}<0.001\right)$. Compared to patients with normal BMI and spKt $N$ within the target range $(1.2-1.4)$, those with low BMI had a higher risk for all-cause mortality at all spKt/N levels. However, the gap in mortality risk became narrower for higher values of spKt $/$. Compared to patients with normal BMl and spKt $N$ in the target range, those with high $\mathrm{BMI}$ and spKt $\mathrm{N}<1.2$ were not at increased risk for mortality despite low dialysis adequacy.
\end{abstract}

Conclusions: The association between spKt/N and mortality in HD patients may be modified by BMI.

Keywords: Body mass index, Dialysis adequacy, Hemodialysis, Mortality

\section{Background}

Despite constant efforts to improve the survival of hemodialysis (HD) patients, which have produced tangible results, their mortality rate remains high $[1,2]$. Several factors affect survival in HD patients, with dialysis adequacy representing one of the most important and modifiable factors $[3,4]$. Single-pool $\mathrm{Kt} / \mathrm{V}_{\text {urea }}(\mathrm{spKt} / \mathrm{V})$, which is urea clearance multiplied by duration of treatment session and normalized for urea distribution volume, is universally employed as a measure of delivered dialysis dose. Among HD patients, values of $\mathrm{spKt} / \mathrm{V}$ less than 1.2 are associated

\footnotetext{
* Correspondence: basara1000@naver.com

Division of Nephrology, Department of Medicine, Samsung Changwon Hospital, Sungkyunkwan University School of Medicine, 158, Paryong-ro, Masanhoewon-gu, 51353 Changwon, Republic of Korea
}

with increased mortality $[5,6]$. Therefore, the National Kidney Foundation-Kidney Dialysis Outcome Quality Initiative (NKF-KDOQI) clinical practice guidelines for dialysis adequacy currently recommend a target spKt/V of 1.4 per session to obtain a minimum delivered $\mathrm{spKt} / \mathrm{V}$ of 1.2 for patients receiving HD on a thrice-weekly schedule [7].

$\mathrm{spKt} / \mathrm{V}$ is inversely correlated with body size because it is normalized for volume of urea distribution. As a result, patients with higher body mass index (BMI) are more likely to have lower $\mathrm{Kt} / \mathrm{V}$, which is associated with increased mortality, and vice versa [8]. Among the general population, obesity is associated with increased mortality and morbidity [9]. However, a higher BMI, taken as an indicator of nutritional status, is paradoxically associated with increased survival in HD patients

(C) The Author(s). 2019 Open Access This article is distributed under the terms of the Creative Commons Attribution 4.0 International License (http://creativecommons.org/licenses/by/4.0/), which permits unrestricted use, distribution, and 
$[10,11]$. Therefore, while $\mathrm{Kt} / \mathrm{V}$ and BMI are negatively correlated, they may affect patient survival in the same direction.

Given that $\mathrm{Kt} / \mathrm{V}$ tends to overestimate and underestimate delivered dialysis among smaller and larger patients, respectively, we sought to examine whether the association of $\mathrm{HD}$ adequacy with mortality differs among patients according to BMI category. In addition, we examined a combination effect of BMI and HD adequacy on mortality risk.

\section{Methods}

\section{Study population}

We retrospectively extracted and examined patient data from the Korean Society of Nephrology registry, a nationwide dataset of medical records of patients with end-stage renal disease (ESRD), from January 1, 2001 to June 31, 2017. Patients 18 years or older receiving maintenance HD on a twice- or thrice-weekly schedule were included in the study cohort. We excluded patients who did not have data on baseline spKt/V and BMI. The time of registry enrollment was set as the time of study enrollment. Patients were followed until death, loss to follow-up, transplantation, or end of study enrollment period (June 2017).

The study was approved by the Institutional Review Committees of Samsung Changwon Hospital, Sungkyunkwan University School of Medicine, who waived the requirement for informed consent.

\section{Demographic and laboratory measurements}

Information on age, sex, ESRD reason (diabetes, hypertension, glomerulonephritis, or others), comorbidities (diabetes, hypertension, and cardiovascular disease), dialysis vintage (from initiation of HD to study enrollment), body weight, height, dialysis adequacy $(\mathrm{spKt} / \mathrm{V})$, dialysis prescription, systolic and diastolic blood pressure (SBP and $\mathrm{DBP}$ ), normalized protein catabolic rate (nPCR), and hemoglobin level were recorded. Demographic data were collected at the time of study enrollment. Clinical and laboratory data within 3 months from study enrollment were collected. Repeated measures of variables for each patient for the 3 months were averaged and used as baseline data.

The spKt/V was calculated as follows: $\mathrm{spKt} / \mathrm{V}=-\ln (\mathrm{R}$ - $0.008 \times \mathrm{t})+(4-3.5 \times \mathrm{R}) \times \mathrm{UF} / \mathrm{W}$, where $\mathrm{R}$ is the ratio of pre- to post-HD concentration of blood urea nitrogen (BUN), $t$ is dialysis session length (in hours), UF is amount of ultrafiltration (L) during the given HD session, and W is post-HD weight $(\mathrm{kg})$. BMI was calculated using postHD body weight in kilograms divided by square of height in meters. Residual kidney function (RKF) expressed in $\mathrm{mL} / \mathrm{min}$ was calculated as follows: collected urine volume $\times$ [urine creatinine/serum creatinine + urine urea/ $(0.25 \times$
post-HD BUN $+0.75 \times$ midweek pre-HD BUN $)] /(2 \times$ urine collection time $\times 60$ ). Urea reduction ratio (URR) was calculated by dividing the difference of pre- and postHD BUN by pre-HD BUN and multiplying by 100 (\%).

\section{Statistical analyses}

Patients were categorized into three groups according to baseline BMI as follows: $<20$ (low), 20 to $<23$ (normal), and $\geq 23$ (high) $\mathrm{kg} / \mathrm{m}^{2}$. Baseline characteristics were described across these BMI groups, and trends across groups were evaluated using linear regression analysis or non-parametric trend tests as appropriate. Baseline $\mathrm{spKt} / \mathrm{V}$ was divided into six categories as follows: $<1.0$, 1.0 to $<1.2,1.2$ to $<1.4,1.4$ to $<1.6,1.6$ to $<1.8$, and $\geq$ 1.8. The association of $\mathrm{spKt} / \mathrm{V}$ with all-cause mortality was examined by Cox proportional hazards regression models using the spKt/V category of 1.2 to $<1.4$ as the reference group. We employed hierarchical adjustment with three models as follows: (1) model 1 included only baseline spKt/V or URR; (2) model 2 included the same variables as model 1 as well as case mix variables of age, sex, dialysis vintage, ESRD etiology (diabetes, hypertension, glomerulonephritis, or others), and comorbidities (diabetes, hypertension, and cardiovascular disease); and (3) model 3 included the same variables as model 2 as well as session time, SBP, DBP, presence of RKF (RKF $\geq 1 \mathrm{~mL} / \mathrm{min}$ ), hemoglobin, and nPCR. The association of $\mathrm{spKt} / \mathrm{V}$ with all-cause mortality according to BMI strata was examined using the methods described above, as well as restricted cubic spline functions with four knots. For sensitivity analyses, we examined the association of all-cause mortality with URR as another index of HD adequacy according to BMI strata. Effect modification on the association of $\mathrm{spKt} / \mathrm{V}$ with all-cause mortality by BMI was evaluated by adding an interaction term to the case mix-adjusted model (model 2).

Missing baseline covariates were dialysis vintage, session time, RKF, SBP, DBP, hemoglobin, and nPCR. The frequency of missing data was less than $11 \%$ for all variables. Baseline missing data were imputed using multiple imputation with 10 imputed datasets and a Cox regression model. All analyses were carried out using STATA version 14.2 (StataCorp LP, College Station, TX, USA).

\section{Results}

\section{Patient characteristics}

Among 19,757 patients who underwent maintenance HD with twice- or thrice-weekly schedule, we excluded 1430 with missing baseline spKt/V data and 85 patients without a baseline BMI measurement. The final study cohort consisted of 18,242 maintenance HD patients (Fig. 1).

The baseline characteristics of the patients according to BMI category are shown in Table 1 . The mean age $( \pm$ SD) was $59 \pm 14$ years, $59 \%$ were male, $43 \%$ had ESRD 
19,757 maintenance hemodialysis (HD) patients

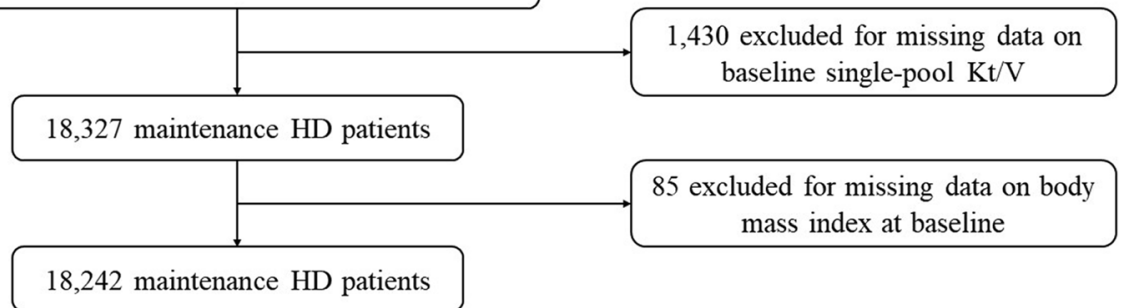

Fig. 1 Cohort design

due to diabetic nephropathy, and the mean baseline $\mathrm{spKt} / \mathrm{V}$ value was $1.4 \pm 0.3$. Patients with higher BMI were more likely to be male, have diabetes and RKF, and tended to have lower spKt/V and URR values but higher hemoglobin and nPCR levels.

\section{Association of spKt/V and all-cause mortality according to body mass index strata}

Among patients on maintenance $\mathrm{HD}$, the median follow-up duration was 5.2 (IQR, 1.9-8.9) years. During this period, we identified 4824 (44.4 per
$1000 \mathrm{pt}$-yrs) all-cause deaths. In restricted cubic spline models, higher spKt/V and BMI were independently associated with lower risk for all-cause mortality, respectively (see Additional file 1: Figure S1). Cox regression analyses showed that, compared to the reference $(\mathrm{spKt} / \mathrm{V} 1.2$ to $<1.4)$, lower and higher baseline spKt/V values were associated with greater and lesser risks for all-cause mortality, respectively; the case mix-adjusted hazard ratios (HRs) and $95 \%$ confidence intervals (CIs) were $1.33(1.19$ 1.49), 1.09 (1.00-1.19), 0.93 (0.86-1.01), $0.86(0.78-$

Table 1 Baseline characteristics of 18,242 hemodialysis patients stratified by baseline body mass index

\begin{tabular}{|c|c|c|c|c|c|}
\hline \multirow[t]{2}{*}{ Variables } & \multicolumn{5}{|c|}{ Body mass index, $\mathrm{kg} / \mathrm{m}^{2}$} \\
\hline & Total & $<20$ & 20 to $<23$ & $\geq 23$ & $P$ value \\
\hline $\mathrm{N}(\%)$ & 18,242 & $5681(31)$ & $6973(38)$ & $5588(31)$ & \\
\hline Age, years & $59 \pm 14$ & $58 \pm 16$ & $59 \pm 14$ & $59 \pm 13$ & 0.383 \\
\hline Male, \% & 59 & 52 & 63 & 61 & $<0.001$ \\
\hline Vintage, year & $1.5(0.5-4.1)$ & $1.9(0.5-5.2)$ & $1.5(0.5-4.2)$ & $1.2(0.4-3.3)$ & $<0.001$ \\
\hline \multicolumn{6}{|l|}{ ESRD reason, \% } \\
\hline Diabetes & 43 & 37 & 43 & 49 & $<0.001$ \\
\hline Hypertension & 19 & 18 & 19 & 20 & 0.031 \\
\hline Glomerulonephritis & 12 & 15 & 12 & 10 & $<0.001$ \\
\hline Others & 26 & 30 & 26 & 21 & $<0.001$ \\
\hline \multicolumn{6}{|l|}{ Comorbidities, \% } \\
\hline Diabetes & 43 & 37 & 43 & 49 & $<0.001$ \\
\hline Hypertension & 30 & 30 & 30 & 29 & 0.088 \\
\hline Cardiovascular disease & 8 & 8 & 8 & 8 & 0.359 \\
\hline Single pool Kt/N & $1.4 \pm 0.3$ & $1.5 \pm 0.4$ & $1.4 \pm 0.3$ & $1.4 \pm 0.3$ & $<0.001$ \\
\hline Urea reduction ratio, \% & $69(64-74)$ & $72(67-76)$ & $69(64-74)$ & $67(63-72)$ & $<0.001$ \\
\hline Treatment time, min & $239 \pm 11$ & $238 \pm 12$ & $239 \pm 10$ & $239 \pm 11$ & $<0.001$ \\
\hline Predialysis SBP, mmHg & $146 \pm 20$ & $145 \pm 20$ & $146 \pm 20$ & $145 \pm 19$ & 0.236 \\
\hline Predialysis DBP, mmHg & $81 \pm 11$ & $82 \pm 11$ & $81 \pm 11$ & $81 \pm 11$ & $<0.001$ \\
\hline Presence of RKF, \% & 6 & 5 & 6 & 7 & $<0.001$ \\
\hline Hemoglobin, g/dL & $10.1 \pm 1.3$ & $9.9 \pm 1.3$ & $10.1 \pm 1.2$ & $10.2 \pm 1.2$ & $<0.001$ \\
\hline $\mathrm{nPCR}, \mathrm{g} / \mathrm{kg} /$ day & $1.0 \pm 0.8$ & $0.9 \pm 0.7$ & $1.0 \pm 0.8$ & $1.0 \pm 0.8$ & $<0.001$ \\
\hline
\end{tabular}

Values for categorical variables are shown as percentages; values for continuous variables, as mean \pm standard deviation or median (interquartile range) Abbreviations: DBP diastolic blood pressure, ESRD end-stage renal disease, $n P C R$ normalized protein catabolic rate, $R K F$ residual kidney function, $S B P$ systolic blood pressure 
Table 2 Adjusted hazard ratios for all-cause mortality according to categorized single-pool Kt/N (spKt/N) among 18,242 hemodialysis patients

\begin{tabular}{|c|c|c|c|c|c|c|}
\hline \multirow[t]{2}{*}{ spKt/N } & \multicolumn{2}{|c|}{ Model 1} & \multicolumn{2}{|c|}{ Model 2} & \multicolumn{2}{|c|}{ Model 3} \\
\hline & HRs & $95 \% \mathrm{Cl}$ & HRs & $95 \% \mathrm{Cl}$ & HRs & $95 \% \mathrm{Cl}$ \\
\hline 1.0 & 1.3 & $1.16-1.45$ & 1.33 & 1.19 & 1.17 & $1.05-131$ \\
\hline 0 to $<1.2$ & 1.05 & 0.96 & 1.08 & 1.00 & 1.03 & 0.9 \\
\hline 1.2 to $<1.4$ & \multicolumn{2}{|c|}{ Reference } & \multicolumn{2}{|c|}{ Reference } & \multicolumn{2}{|c|}{ Reference } \\
\hline 4 to $<1.6$ & 0.92 & $0.85-1.00$ & 0.93 & $0.86-1.01$ & 0.95 & $0.87-1.02$ \\
\hline .6 to $<1.8$ & 0.85 & $0.78-0.94$ & 0.86 & $0.78-0.95$ & 0.89 & $0.81-0.98$ \\
\hline$\geq 1.8$ & 0.85 & $0.76-0.94$ & 0.86 & $0.77-0.96$ & 0.88 & $0.79-0.99$ \\
\hline
\end{tabular}

Model 1: Adjusted for only baseline spKt $/ \mathrm{V}$

Model 2: Adjusted for covariates of model 1 and age, sex, dialysis vintage, end-stage renal disease reason (diabetes, hypertension, glomerulonephritis, or others), and comorbidities (diabetes, hypertension, and cardiovascular disease) Model 3: Adjusted for covariates of model 2 and session time, systolic blood pressure, diastolic blood pressure, presence of residual kidney function (renal urea clearance $\geq 1 \mathrm{~mL} / \mathrm{min}$ ), hemoglobin, and normalized protein catabolic rate
$0.95)$, and $0.86(0.77-0.96)$ for $\mathrm{spKt} / \mathrm{V}$ values $<1.0$, 1.0 to $<1.2,1.4$ to $<1.6,1.6$ to $<1.8$, and $\geq 1.8$, respectively (Table 2). We found that the association of baseline spKt/V with all-cause mortality was significantly modified by BMI $\left(P_{\text {interaction }}<0.001\right)$. Among patients with low $\left(<20 \mathrm{~kg} / \mathrm{m}^{2}\right)$ and normal BMI $\left(20\right.$ to $<23 \mathrm{~kg} / \mathrm{m}^{2}$ ), higher $\mathrm{spKt} / \mathrm{V}$ was associated with lower all-cause mortality compared to the reference group in all adjusted models (Fig. 2a and b). On the other hand, among patients with high BMI $\left(\geq 23 \mathrm{~kg} / \mathrm{m}^{2}\right)$, the association between higher $\mathrm{spKt} / \mathrm{V}$ and lower all-cause mortality was attenuated in all adjusted models (Fig. 2c). The association between continuous spKt/V level and mortality according to BMI strata was also robust in the restricted cubic spline models (see Additional file 1: Figure S2). These results were consistent even after restricting the analysis to only those patients receiving thrice-weekly HD $(n=16,182)$ (see Additional file 1: Table S1).
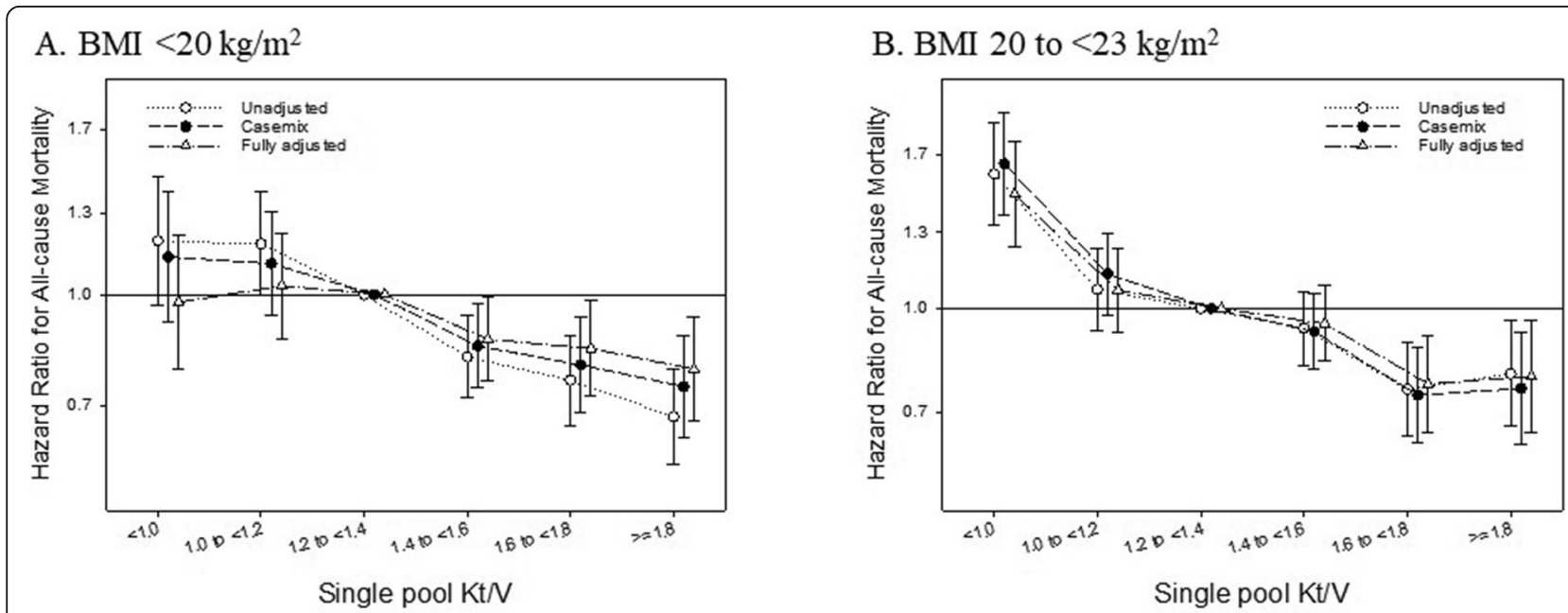

\section{BMI $\geq 23 \mathrm{~kg} / \mathrm{m}^{2}$}

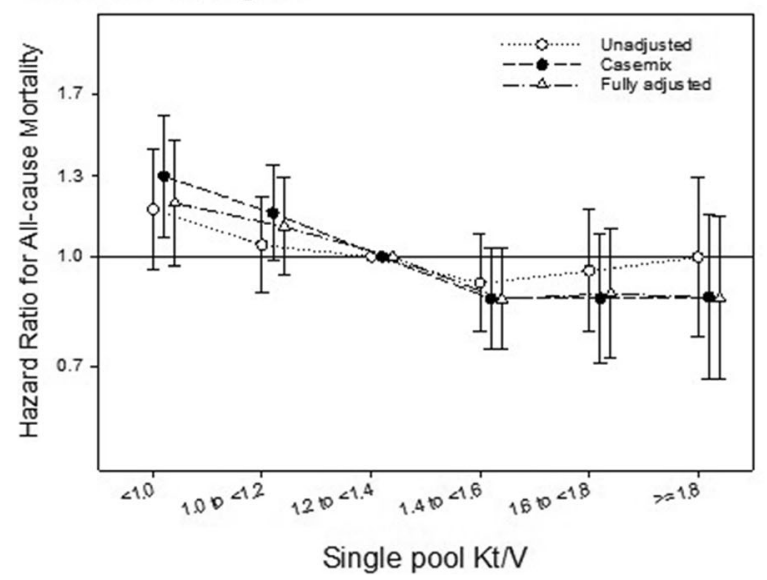

Fig. 2 Single-pool Kt $/ \mathrm{N}$ and hazard ratios (95\% confidence intervals) for all-cause mortality stratified by baseline body mass index (BMI) $<20 \mathrm{~kg} /$ $\mathrm{m}^{2}, 20$ to $<23 \mathrm{~kg} / \mathrm{m}^{2}$, and $\geq 23 \mathrm{~kg} / \mathrm{m}^{2}$ (a, $\mathbf{b}$, and $\mathbf{c}$, respectively) among 18,242 hemodialysis patients 


\section{All-cause mortality in relation to body mass index and spKt/V}

Compared to patients with normal BMI (20 to $\left.<23 \mathrm{~kg} / \mathrm{m}^{2}\right)$ and $\mathrm{spKt} / \mathrm{V}$ within the target range of 1.2 to $<1.4$, those with low BMI $\left(<20 \mathrm{~kg} / \mathrm{m}^{2}\right)$ had higher risk for all-cause mortality for all spKt/V categories (Fig. 3). However, increasing spKt/V values was associated with gradual narrowing of the gap in mortality risk. Compared to patients with normal BMI and spKt/V within the target range, those with high BMI $\left(\geq 23 \mathrm{~kg} / \mathrm{m}^{2}\right)$ and spKt $/ \mathrm{V}<1.2$ did not have increased risk for mortality despite low dialysis adequacy. Moreover, patients with high $\mathrm{BMI}$ and $\mathrm{spKt} / \mathrm{V} \geq 1.2$ were at lower risk for all-cause mortality compared to those with normal $\mathrm{BMI}$ and $\mathrm{spKt} / \mathrm{V}$ within the target range. However, increasing the spKt/V beyond that did not afford any additional survival benefit compared to the next lower spKt $/ \mathrm{V}$ category among HD patients with high BMI.

\section{Sensitivity analysis by urea reduction ratio as an index of hemodialysis adequacy}

The median (IQR) baseline URR in our cohort was 69 (64$74) \%$. The association of URR with all-cause mortality was also modified by BMI, which was consistent with the finding of spKt $/ \mathrm{V}$ (Fig. 4). Among patients with low $\left(<20 \mathrm{~kg} / \mathrm{m}^{2}\right)$ or normal BMI $\left(20\right.$ to $\left.<23 \mathrm{~kg} / \mathrm{m}^{2}\right)$, higher URR was associated with lower risk for all-cause mortality compared to the reference group (URR 65 to $<70$ ). On the other hand, the association of higher URR with lower mortality was attenuated among patients with high BMI $\left(\geq 23 \mathrm{~kg} / \mathrm{m}^{2}\right)$.

\section{Discussion}

The results of the present study suggest that the effect of dialysis adequacy on mortality among maintenance HD patients may be modified by BMI. In the high BMI group, the association between dialysis adequacy and mortality was attenuated. Moreover, we identified a combination effect of BMI and spKt/V on mortality. Specifically, patients with low BMI had higher mortality risk even when they had higher spKt/V compared to those with normal BMI and spKt/V within the target range. In contrast, patients with high $\mathrm{BMI}$ tended to have lower mortality risk at any level of spKt/V compared to those with normal BMI and spKt/V within the target range, but there was no additional benefit on mortality of spKt/V value higher than the target range.

Current clinical practice guidelines recommend a target spKt/V of 1.2 to 1.4 per session [7]. According to the results of the Hemodialysis (HEMO) study, doses of dialysis beyond the recommended target dose appear to have minimal benefit on survival [12]. However, the association between dialysis dose and survival may not be uniform across all patients [13]. In our study, there was a significant positive association between higher spKt/V above the target and improved survival among $\mathrm{HD}$ patients with $\mathrm{BMI}<23$ (low and normal $\mathrm{BMI})$. In contrast, survival in the high BMI group was not significantly improved at higher doses of dialysis. These results are similar to findings described by Port et al., who identified a significant association between higher URR and improved survival in small and medium BMI groups

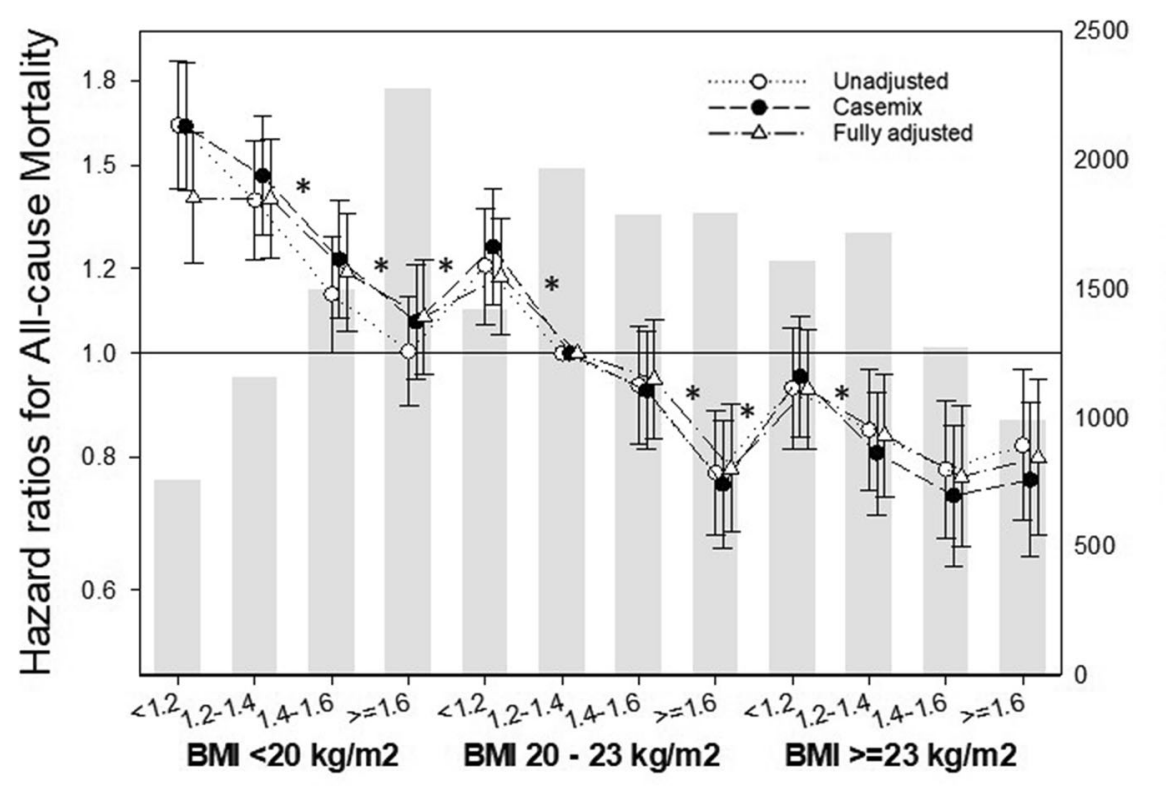

Body Mass Index and Single-Pool Kt/V

Fig. 3 Hazard ratios (95\% confidence intervals) for all-cause mortality according to body mass index (BMI) and single-pool Kt $N{ }^{*} P<0.05$ compared with the previous level 


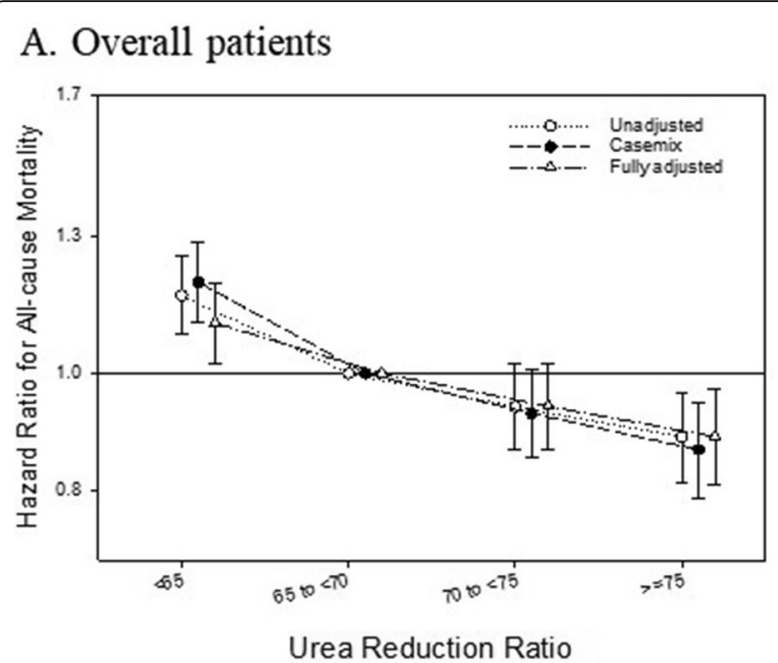

B. BMI $<20 \mathrm{~kg} / \mathrm{m}^{2}$

\section{BMI 20 to $<23 \mathrm{~kg} / \mathrm{m}^{2}$}
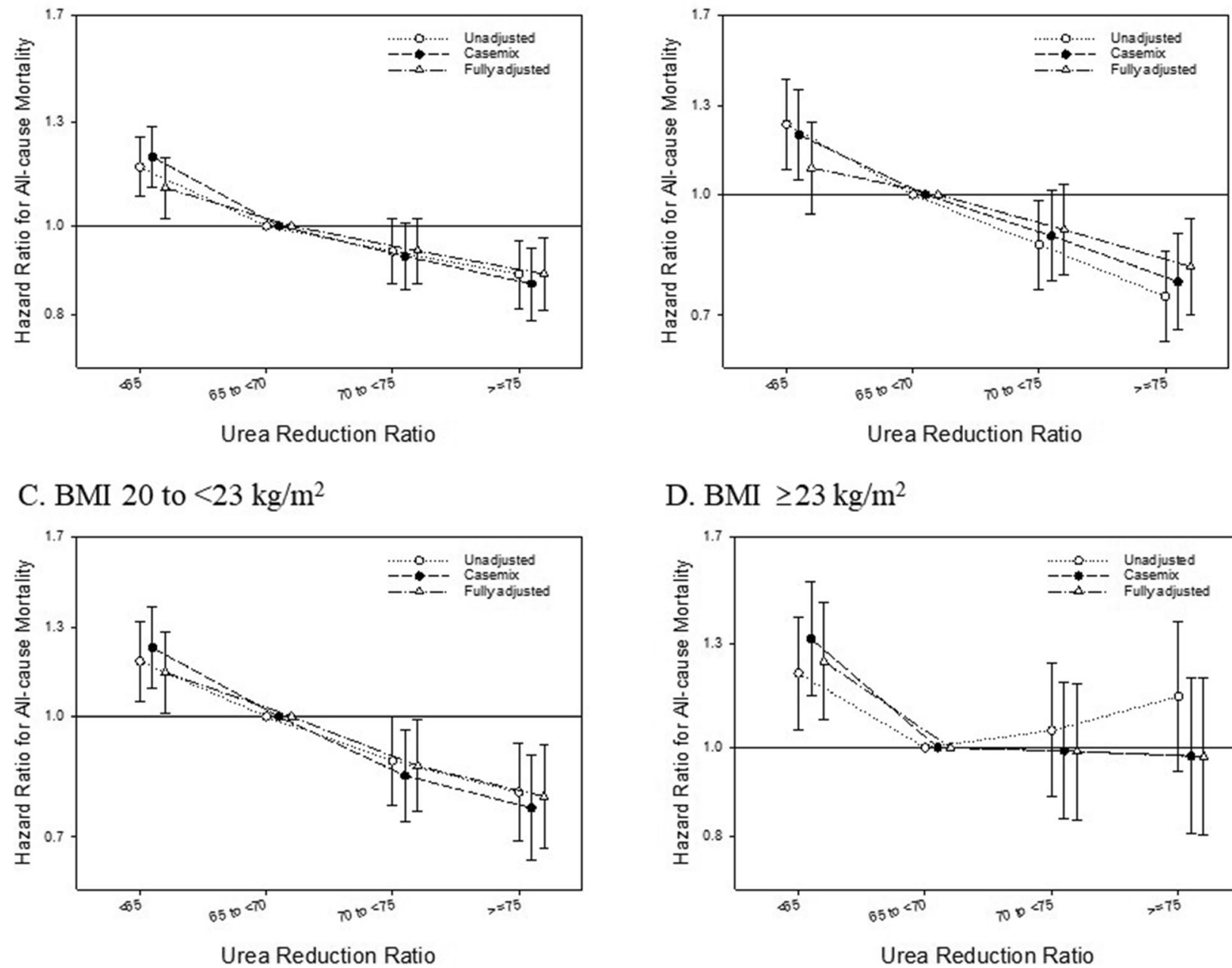

D. BMI $\geq 23 \mathrm{~kg} / \mathrm{m}^{2}$

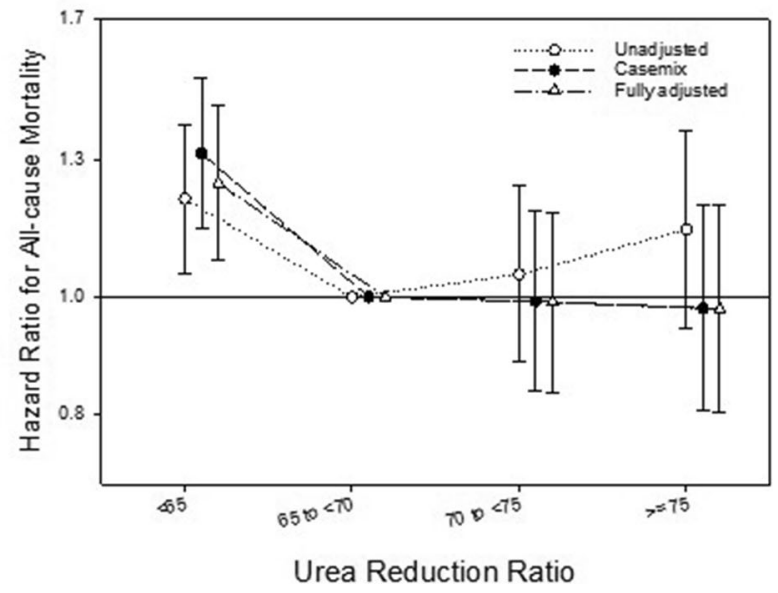

Fig. 4 Urea reduction ratio as an alternative index of dialysis adequacy and associated hazard ratio (95\% confidence interval) for all-cause mortality in overall cohort (a) and patients with body mass index (BMI) $<20 \mathrm{~kg} / \mathrm{m}^{2}, 20$ to $<23 \mathrm{~kg} / \mathrm{m}^{2}$, and $\geq 23 \mathrm{~kg} / \mathrm{m}^{2}$ (b, c, and d , respectively)

receiving $\mathrm{HD}$, with the exception of the highest BMI group, in which the mortality risk plateaued in the highest URR category [14]. In addition, Wang et al. reported that increasing dialysis dose in overweight HD patients does not lead to improved health-related quality of life [15].

The differences between the low and high BMI groups observed in our study may be explained in several ways. First, malnutrition-inflammation complex syndrome and protein energy wasting likely account for the relationship between lower BMI and greater mortality among dialysis patients $[10,16]$. Indeed, improvement of dialysis adequacy has been associated with better nutritional status as assessed by nPCR and serum albumin, which together are linked to greater survival [17]. However, high BMI is also likely indicative of good nutritional condition and is less likely to be affected by the beneficial effects related to higher dialysis adequacy. Post-dialysis urea rebound and rate of urea generation represent a second explanation for the differences observed in our study according to BMI group. Specifically, spKt/V can overestimate the delivered $\mathrm{KtV}$ by up to $15-40 \%$ due to the post-dialysis urea rebound phenomenon $[18,19]$. Smaller patients who have a lower urea distribution volume tend to experience higher post-dialysis urea rebound [20]. Increased spKt/V may also help achieve a more appropriate delivered $\mathrm{Kt} / \mathrm{V}$ in smaller patients. Furthermore, uremic toxin generation per unit of body mass is greater in patients with low body mass. Therefore, the concentration of uremic toxins in body fluid tends to be greater in small patients, who in turn may have higher requirement for dialysis [21, 22].

By simultaneously considering BMI and spKt/V, our results showed a higher mortality rate in patients with low BMI for any spKt/V compared to patients with normal BMI and $\mathrm{spKt} / \mathrm{V}$ within the target range. In addition, patients 
with low BMI benefited from a higher dialysis dose. In contrast, patients with high BMI had lower mortality at all levels of spKt/V compared to patients with normal BMI and spKt/ $\mathrm{V}$ within the target range, with the difference in effects in patients with $\mathrm{spKt} / \mathrm{V}<1.2$ failing to reach statistical significance. The negative effect of underdialysis in overweight HD patients might have been counteracted by high BMI itself. This possibility is partially supported by the results of Owen et al., who reported that lower URR is not associated with increased mortality in African Americans with higher BMI and better nutrition status compared to Caucasians [13]. Therefore, our results indicate that the impact on mortality derived from nutritional status by higher BMI may outbalance the impact of given HD dose on mortality.

Our study has several potential limitations that should be addressed. First, although we adjusted for several confounding factors to examine the association between $\mathrm{spKt} / \mathrm{V}$ and mortality modified by BMI, we were unable to exclude the presence of residual confounding factors due to the observational nature of the study. In particular, serum albumin or inflammatory markers associated with malnutrition-inflammation complex syndrome and mortality were not included in the analysis because of missing data. In addition, body weight and dialysis adequacy may change over time. Therefore, we were unable to prove causation. Second, we did not consider RKF when calculating spKt/V. HD patients with RKF may have better survival rates despite low spKt/V; however, such a case would likely have biased our results toward the null.

\section{Conclusions}

Our study shows that the association between dialysis adequacy assessed by spKt/V and mortality in HD patients may be modified by BMI. Patients with low or normal BMI experienced a decreased risk of mortality by increasing spKt/V above target, while those with high BMI gained no additional benefit from increasing spKt/V above the target. This study highlights the need for individualized spKt/V targets in HD patients and a flexible approach to treatment targets during patient-centered care. Further clinical trials are needed to confirm our results and to elucidate the causative nature of the associations observed in this study.

\section{Supplementary information}

Supplementary information accompanies this paper at https://doi.org/10. 1186/s12882-019-1570-0

Additional file 1: Table S1. Case mix-adjusted hazard ratios for allcause mortality according to categorized single-pool Kt/N (spKt/N) among 16,182 thrice-weekly hemodialysis patients stratified by body mass index. Figure S1. Case mix-adjusted restricted cubic spline model showing hazard ratios for all-cause mortality according to baseline single-pool Kt/N level and body mass index. Figure $\mathbf{S 2}$. Case mix-adjusted restricted cubic spline model showing hazard ratios for all-cause mortality by baseline single-pool Kt/N level according to body mass index (BMI).

\section{Abbreviations}

BMI: Body mass index; BUN: Blood urea nitrogen; DBP: Diastolic blood pressure; ESRD: End-stage renal disease; HD: Hemodialysis; IQR: Interquartile range; NKF-KDOQI: National Kidney Foundation-Kidney Dialysis Outcome Quality Initiative; nPCR: normalized protein catabolic rate; RKF: Residual kidney function; SBP: Systolic blood pressure; spKt/N: single-pool Kt/Nureai UF: Ultrafiltration; URR, urea reduction ratio

\section{Acknowledgements}

Not applicable.

\section{Authors' contributions}

YJ contributed to conception and design of the study, conducted all statistical analyses, interpreted results and wrote this original article. WP contributed to conception and design of the study and revised the manuscript. Both authors read and approved the final manuscript.

\section{Funding}

This research was supported by the Basic Science Research Program through the National Research Foundation of Korea (NRF) funded by the Ministry of Education, Science and Technology (2017R1C1B5074033).

The funders did not play a role in study design, data collection, analysis, reporting, or the decision to submit for publication.

\section{Availability of data and materials}

The data that support the findings of this study were used under license for the current study from the Korean Society of Nephrology and are not publicly available. Data are, however, available from the authors upon reasonable request and with permission of the Korean Society of Nephrology.

\section{Ethics approval and consent to participate}

We used deidentified patient data from the Kidney Society of Nephrology registry. The study was approved by the Institutional Review Committees of Samsung Changwon Hospital, Sungkyunkwan University School of Medicine, who waived the requirement for informed consent (IRB No.: 2019-03-008).

Consent for publication

Not applicable.

Competing interests

The authors declare that they have no competing interests.

Received: 14 May 2019 Accepted: 27 September 2019

Published online: 22 October 2019

\section{References}

1. Jin DC, Yun SR, Lee SW, Han SW, Kim W, Park J, et al. Current characteristics of dialysis therapy in Korea: 2016 registry data focusing on diabetic patients. Kidney Res Clin Pract. 2018;37(1):20-9.

2. Jassal SV, Trpeski L, Zhu N, Fenton S, Hemmelgarn B. Changes in survival among elderly patients initiating dialysis from 1990 to 1999. CMAJ. 2007; 177(9):1033-8.

3. Duong TV, Wu PY, Wong TC, Chen HH, Chen TH, Hsu YH, et al. Mid-arm circumference, body fat, nutritional and inflammatory biomarkers, blood glucose, dialysis adequacy influence all-cause mortality in hemodialysis patients: a prospective cohort study. Medicine (Baltimore). 2019;98(12): e14930.

4. Natoli JL, Boer R, Nathanson BH, Miller RM, Chiroli S, Goodman WG, et al. Is there an association between elevated or low serum levels of phosphorus, parathyroid hormone, and calcium and mortality in patients with end stage renal disease? A meta-analysis. BMC Nephrol. 2013;14:88.

5. Gotch FA, Levin NW, Port FK, Wolfe RA, Uehlinger DE. Clinical outcome relative to the dose of dialysis is not what you think: the fallacy of the mean. Am J Kidney Dis. 1997;30(1):1-15.

6. Owen WF Jr, Lew NL, Liu Y, Lowrie EG, Lazarus JM. The urea reduction ratio and serum albumin concentration as predictors of mortality in patients undergoing hemodialysis. N Engl J Med. 1993;329(14):1001-6.

7. National Kidney F. KDOQI clinical practice guideline for hemodialysis adequacy: 2015 update. Am J Kidney Dis. 2015;66(5):884-930. 
8. Salahudeen AK, Fleischmann EH, Bower JD. Impact of lower delivered Kt/N on the survival of overweight patients on hemodialysis. Kidney Int. 1999; 56(6):2254-9.

9. Kong KA, Park J, Hong SH, Hong YS, Sung YA, Lee H. Associations between body mass index and mortality or cardiovascular events in a general Korean population. PLoS One. 2017;12(9):e0185024.

10. Kalantar-Zadeh K, Streja E, Kovesdy CP, Oreopoulos A, Noori N, Jing J, et al. The obesity paradox and mortality associated with surrogates of body size and muscle mass in patients receiving hemodialysis. Mayo Clin Proc. 2010; 85(11):991-1001.

11. Kim S, Jeong JC, Ahn SY, Doh K, Jin DC, Na KY. Time-varying effects of body mass index on mortality among hemodialysis patients: results from a nationwide Korean registry. Kidney Res Clin Pract. 2019:38:90-9.

12. Eknoyan G, Beck GJ, Cheung AK, Daugirdas JT, Greene T, Kusek JW, et al. Effect of dialysis dose and membrane flux in maintenance hemodialysis. N Engl J Med. 2002;347(25):2010-9.

13. Owen WF Jr, Chertow GM, Lazarus JM, Lowrie EG. Dose of hemodialysis and survival: differences by race and sex. JAMA. 1998;280(20):1764-8.

14. Port FK, Ashby VB, Dhingra RK, Roys EC, Wolfe RA. Dialysis dose and body mass index are strongly associated with survival in hemodialysis patients. $J$ Am Soc Nephrol. 2002;13(4):1061-6.

15. Wang W, Tonelli M, Hemmelgarn B, Gao S, Johnson JA, Taub K, et al. The effect of increasing dialysis dose in overweight hemodialysis patients on quality of life: a 6-week randomized crossover trial. Am J Kidney Dis. 2008; 51(5):796-803

16. Kovesdy CP, Kalantar-Zadeh $\mathrm{K}$. Why is protein-energy wasting associated with mortality in chronic kidney disease? Semin Nephrol. 2009;29(1):3-14.

17. Schulman $\mathrm{G}$. The dose of dialysis in hemodialysis patients: impact on nutrition. Semin Dial. 2004;17(6):479-88.

18. Smye SW, Dunderdale E, Brownridge G, Will E. Estimation of treatment dose in high-efficiency haemodialysis. Nephron. 1994;67(1):24-9.

19. Spiegel DM, Baker PL, Babcock S, Contiguglia R, Klein M. Hemodialysis urea rebound: the effect of increasing dialysis efficiency. Am J Kidney Dis. 1995; 25(1):26-9.

20. Jean G, Chazot C, Charra B, Terrat JC, Vanel T, Calemard E, et al. Is postdialysis urea rebound significant with long slow hemodialysis? Blood Purif. 1998;16(4):187-96

21. Sridharan S, Vilar E, Berdeprado J, Farrington K. Energy metabolism, body composition, and urea generation rate in hemodialysis patients. Hemodial Int. 2013;17(4):502-9.

22. Kotanko P, Levin NW. The impact of visceral mass on survival in chronic hemodialysis patients. Int J Artif Organs. 2007;30(11):993-9.

\section{Publisher's Note}

Springer Nature remains neutral with regard to jurisdictional claims in published maps and institutional affiliations.

Ready to submit your research? Choose BMC and benefit from:

- fast, convenient online submission

- thorough peer review by experienced researchers in your field

- rapid publication on acceptance

- support for research data, including large and complex data types

- gold Open Access which fosters wider collaboration and increased citations

- maximum visibility for your research: over $100 \mathrm{M}$ website views per year

At $\mathrm{BMC}$, research is always in progress.

Learn more biomedcentral.com/submissions 